Estudio revela sesgo en las conclusiones de los ensayos clínicos de patrocinio industrial

Se ha observado por mucho tiempo que las conclusiones derivadas de ensayos clínicos patrocinados por el sector industrial tienden a favorecer al fabricante del producto estudiado. La asociación entre el patrocinio industrial y conclusiones favorables para la industria se ha visto incluso confirmada por una serie de revisiones bibliográficas sistemáticas que se han limitado a señalar el fenómeno, sin examinar si las conclusiones favorables reflejan los resultados cuantitativos de los estudios en términos de eficacia terapéutica o ausencia de efectos adversos. La tarea de explorarlo a fondo fue asumida recientemente por investigadores en Dinamarca, quienes examinaron aleatoriamente 167 revisiones bibliográficas sacadas de la base de datos Cochrane en mayo de 2001 y, para cada uno de los 370 ensayos incluidos en las revisiones, anotaron las conclusiones, la fuente de financiamiento, el efecto terapéutico observado, las reacciones adversas y otros factores de confusión. La conclusión de cada estudio, que fue la principal variable de interés, se trató como variable binaria para fines del análisis, reduciéndose a si los autores recomendaban o no el medicamento como tratamiento de elección. El objetivo del estudio fue determinar si la asociación entre la fuente de financiamiento y las conclusiones de los ensayos clínicos examinados se veía determinada por los efectos terapéuticos del medicamento estudiado o por la escasez de efectos adversos.

El medicamento experimental fue recomendado como tratamiento de elección en $51 \%$ de los ensayos clínicos patrocinados por la industria farmacéutica, $35 \%$ de los ensayos patrocinados conjuntamente por entidades con y sin fines de lucro, 30\% de los ensayos cuya fuente de financiamiento se desconocía y $16 \%$ de los ensayos patrocinados por entidades sin fines de lucro $\left(P<0,001\right.$; prueba de $\left.\chi^{2}\right)$. La regresión logística reveló que la fuente de financiamiento, el efecto terapéutico y el doble enmascaramiento eran las únicas variables con valor pronóstico con respecto a las conclusiones. En los ensayos clínicos financiados por organizaciones con fines de lucro se observó una tendencia cinco veces mayor a recomendar el medicamento experimental como tratamiento de elección que en los ensayos financiados por entidades sin fines de lucro. El hallazgo más interesante fue que las asociaciones observadas no mostraban relación con los resultados en términos de la eficacia del medicamento o la escasez de efectos adversos, a partir de lo cual cabe concluir que las conclusiones favorables para el fabricante eran producto de un sesgo en la interpretación de los resultados del ensayo y no necesariamente consecuencia de los resultados mismos. Es de rigor que quienes leen ensayos clínicos patrocinados por compañías comerciales examinen con ánimo crítico las conclusiones de dichos ensayos a fin de determinar si se ven debidamente respaldadas por los resultados. (Als-Nielsen B, et al. Association of funding and conclusions in randomized drug trials: a reflection of treatment effect or adverse events? JAMA 2003;290:921-928.)

\section{Nueva mutación de Leishmania major facilita el estudio de la infección parasitaria persistente}

La infección por Leishmania spp. tiene una fase aguda y sintomática en la cual los promastigotos del parásito se reproducen dentro de los macrófagos del huésped y se convierten en amastigotos con la capacidad de sobrevivir indefinidamente dentro de los lisosomas de esos fagocitos, pudiendo años más tarde producir una reactivación de la infección con síntomas mucho más intensos que los de la infección inicial. De hecho, la reactivación de la infección latente da origen a los cuadros más graves de leishmaniasis, entre ellos la variante cutánea que es secuela del kala azar. Aunque se sabe que ciertos factores propios del huésped, entre ellos la presencia de interleucina 10, facilitan la presencia persistente del parásito en el organismo, es relativamente poco lo que se sabe acerca de los factores parasitarios que contribuyen a esa persistencia. Según observaciones recientes, una cepa de Leishmania carente de fosfoglucanos $\left(\operatorname{lpg} 2^{-}\right)$tras manipulación genética puede permanecer latente en el organismo humano sin causar síntomas de enfermedad y puede ser la clave para la exploración de los fac- 
tores parasitarios que determinan la permanencia asintomática de Leishmania en el organismo.

Los fosfoglucanos, moléculas ubicadas en la superficie del parásito Leishmania, son constituyentes de una envoltura densa que protege al parásito y a la vez le confiere virulencia. Su pérdida deja al parásito desprotegido frente al complemento y a otros mecanismos de defensa del huésped y le impide sobrevivir dentro de los macrófagos indefinidamente.

La importancia de los fosfoglucanos para la supervivencia parasitaria fue examinada por investigadores de la Universidad de Nueva York en un estudio con parásitos de Leishmania desprovistos de fosfoglucanos mediante una deleción genética intencionada (Leishmania major $\operatorname{lpg} 2^{-}$). Los investigadores observaron el efecto de la deleción sobre la supervivencia del parásito en los flebótomos que transmiten la infección al ser humano y observaron que al cabo de 3 días dicha supervivencia era 10 veces menor que la de parásitos normales y que pasado ese período el parásito desaparecía por completo. Los investigadores también observaron el comportamiento de los parásitos en macrófagos, donde tampoco pudieron sobrevivir. En cambio, cuando los parásitos mutantes fueron inyectados en ratones genéticamente susceptibles a la leishmaniasis, estos últimos permanecieron asintomáticos y se pensó que el parásito había desaparecido como en los demás casos. Más tarde se descubrió, sorprendentemente, que había parásitos en muestras de tejido obtenidas de estos ratones, deduciéndose que algún tipo de célula distinta de un macrófago le permite al parásito sobrevivir y proliferar sin causar síntomas de enfermedad. En este momento los investigadores están dedicados a buscar esa célula y a estudiar las implicaciones de estos hallazgos desde el punto de vista de la factibilidad de elaborar una vacuna contra la leishmaniasis. En última instancia, Leishmania lpg2- parece ser un modelo promisorio para estudiar los mecanismos que conducen a la infección asintomática persistente en el ser humano. (Späth GF, et al. Persistence without pathology in phosphoglycan-deficient Leishmania major. Science 301(5637):1241-1249.)

\section{El efecto de la pérdida de peso sobre la tensión arterial}

Aunque en general se sabe que el exceso de peso corporal es un factor de riesgo de hipertensión arterial, se han efectuado pocos estudios para determinar el efecto a largo plazo de la pérdida de peso en la tensión arterial. En un estudio prospectivo de 4 años de duración que acaba de concluir y que fue realizado por investigadores de la Universidad de Perugia, Italia, se observó el efecto de la pérdida de peso en la tensión arterial medida durante 24 horas y en la masa miocárdica, que sufre un aumento compensatorio anormal cuando la hipertensión arterial crónica crea una resistencia continua a la expulsión de la sangre del ventrículo izquierdo. Los investigadores estudiaron a 181 personas hipertensas con sobrepeso (índice de masa corporal de 25 a $39 \mathrm{~kg} / \mathrm{m}$; tensión arterial de 145/94 $\pm 12 / 7 \mathrm{~mm} \mathrm{Hg}$ ) que nunca habían sido tratadas con antihipertensivos y que no recibieron medicamentos de este tipo en ningún momento durante el estudio. Las principales variables de interés fueron el cambio de la tensión arterial medida durante 24 horas y de la masa ventricular izquierda determinada por ecocardiograma. A los pacientes se les hicieron determinaciones de tensión arterial y de masa ventricular izquierda en dos ocasiones: en el momento de entrar en el estudio y 3,8 \pm 2 años después (uno como mínimo).

Se encontró una asociación directa estadísticamente significativa $(P<0,001)$ entre el porcentaje de peso corporal perdido y la reducción porcentual de la tensión arterial sistólica y diastólica a lo largo de 24 horas. Aunque también se observó una asociación entre la magnitud de la pérdida de peso y a tensión arterial medida en el consultorio, dicha asociación fue menos marcada. Los pacientes que perdieron peso durante el seguimiento, de los cuales hubo un total de 106, mostraron un aumento mucho más leve de la tensión arterial medida durante 24 horas y de la masa ventricular izquierda a lo largo del período de seguimiento que los demás participantes del estudio. Una regresión lineal múltiple reveló que una pérdida de peso de $10 \%$ podía pronosticar, por sí sola, un descenso de la tensión arterial sistólica/diastólica a lo largo de 24 horas de 4,3/3,8 $\mathrm{mm} \mathrm{Hg}$. En términos resumidos, el adelgazamiento parece reducir la tensión arterial y la masa ventricular y se aconseja en personas que no pueden $o$ desean recibir tratamiento medicamentoso. (Schillaci D, et al. Effect of body weight changes on 24-hour blood pressure and left ventricular mass in hypertension: a 4-year followup. Am J Hypertens 2003; 16(8):634-639.)

\section{Impacto económico y sanitario de una vacuna contra el virus del papiloma humano}

Según los resultados de estudios recientes, es posible que en el próximo decenio se encuentre una vacuna contra el virus del papiloma humano (VPH). Ciertos subtipos del virus, particularmente 
los tipos 16, 18, 31 y 45, se asocian con el cáncer cervicouterino debido a su capacidad para producir cambios degenerativos que llevan, durante un proceso que demora años, a la transformación maligna de las céulas cervicales infectadas. Una vacuna con la capacidad para prevenir la infección por estos virus podría reducir enormemente la incidencia de cáncer cervicouterino y de sus lesiones precursoras, para los cuales la única medida preventiva que existe en la actualidad es la detección temprana de células anormales mediante el frotis de Papanicolaou. El uso cada vez más frecuente de esta prueba lleva a la detección de anomalías cervicales inflamatorias y precancerosas que requieren atención y que se traducen en un aumento de los costos en relación con los beneficios del tamizaje. Por este motivo, se recomienda practicar el Papanicolaou solo en mujeres mayores de 30 años.

Los resultados que despiertan la esperanza de encontrar una vacuna relativamente pronto derivan de un reciente ensayo clínico de fase 2 donde se exploró el efecto de una vacuna contra la infección por VPH. En este ensayo, la vacuna puesta a prueba se mostró eficaz contra la infección crónica por VPH 16 en $100 \%$ de los casos (intervalo de confianza de $95 \%$ : $90 \%$ a $100 \%$ ) durante un período de seguimiento mediano de 17,4 meses. Actualmente se están llevando a cabo ensayos clínicos más extensos de fase 3 destinados a explorar la eficacia de vacunas contra diversos tipos de virus oncógenos. Aunque sus resultados tardarán en revelarse, se pueden construir modelos matemáticos para identificar las variables que podrían tener el mayor impacto sobre los costos y beneficios de la vacunación y servir de base para incorporar la aplicación de una vacuna eficaz en los actuales programas de tamizaje de cáncer cervicouterino. De hecho, un modelo de este tipo (modelo Markov) ha sido creado en Estados Unidos por un grupo de investigadores que con él buscaron examinar los posible efectos sanitarios y económicos de integrar la administración de una vacuna contra el VPH a los programas habituales de tamizaje contra la enfermedad. El modelo les permitió simular la historia natural de la infección por VPH de alto y bajo riesgo, así como la del cáncer del cuello de útero, en una cohorte ficticia de niñas vírgenes sanas con una edad inicial de 12 años que fueron observadas hasta la edad de 85 años. Por este medio los investigadores fueron calculando, para cada año de vida, el riesgo de adquirir la infección por algún tipo peligroso o inocuo de $\mathrm{VPH}$, de llegar a tener una infección crónica por VPH, de tener una neoplasia cervical intraepitelial de grado 1, 2 ó 3, y de tener un cáncer invasor de cuello uterino, integrando a la vez en el modelo las posibilidades de morir o de sufrir una histerectomía por razones ajenas al cáncer. Dando por sentado que el frotis de cuello uterino tiene una sensibilidad de $55,6 \%$ y una especificidad de $95,7 \%$, como han demostrado algunos estudios, los investigadores compararon tres estrategias: 1) la administración de una vacuna solamente; 2) el uso exclusivo del examen citológico convencional (frotis de Papanicolaou) y 3) la vacunación seguida del tamizaje citológico. En dos de las estrategias se incorporó una vacuna dirigida contra una fracción específica de VPH de alto riesgo (oncógenos) y los intervalos escogidos entre tamizajes fueron 1, 2, 3 y 5 años. Las edades elegidas para iniciar el tamizaje en el modelo fueron los 18, 22, 24, 26 y 30 años.

Según los resultados, ni la vacunación solamente ni la vacunación seguida del tamizaje citológico cada 3 ó 5 años se mostró eficaz, a diferencia de intervalos más cortos entre los tamizajes posteriores a la vacunación. La mejor razón de costo a efectividad (US\$ 44889 ) se obtuvo con la vacunación a los 24 años de edad más el tamizaje bianual aventajando al tamizaje exclusivo iniciado a los 18 años de edad y practicado cada tres años sucesivamente. No obstante, la estrategia de una vacunación inicial a los 18 años seguida de un tamizaje citológico anual se asoció con la mayor reducción general de la incidencia de cáncer cervicouterino y de la mortalidad por la enfermedad, a un costo de $\$ 236250$ por cada año de vida ganado en comparación con la vacunación inicial a los 22 años seguida de un tamizaje anual. Cabe concluir que la vacunación contra el VPH combinada con el tamizaje puede ser efectiva en función del costo durante los años de mayor susceptibilidad a la infección por tipos peligrosos de VPH. No obstante, hace falta investigar más a fondo la edad ideal para administrar la vacuna. (Kulasingam SL, et al. Potential health and economic impact of adding a human papillomavirus vaccine to screening programs. JAMA 2003;290:781-789.) 